be found to have a normal pulmonary artery and an infarcted myocardium.

Those who collapse and remain very ill require surgical treatment, or possibly thrombolytic therapy. ${ }^{78}$ But there is usually time for diagnostic investigations, ${ }^{9}$ and emergency pulmonary angiography is of great help. Embolectomy can then be done, and this is the group of patients in whom the best results are obtained. ${ }^{10}$ It is difficult to decide when to operate, but failure to improve over one to three hours, with bypotension and a raised central venous pressure, are sound indications for surgery.

The third group, collapse followed by fairly rapid recovery, presents many problems. Though surgery is not needed to save life, two great risks threaten these patients. Firstly, there may be another embolus waiting in the legs which, added to the first, could kill (second emboli occur in 30\% of patients). ${ }^{11}$ Secondly, early cardiovascular recovery does not mean that the patient will ultimately attain normal health. D. Phear ${ }^{12}$ has shown that $30 \%$ of patients who survive a major embolism have persistent and sometimes disabling dypsnoea, due either to the initial embolus or to recurrent small subclinical emboli. It seems reasonable to suggest that these patients should have their peripheral veins studied, as suggested by N. L. Browse and his colleagues (p. 596), and a pulmonary angiogram done, and then be considered for thrombolytic therapy or surgery. How much time is available for these investigations before the thrombus becomes so adherent that it is irremovable? The paper by Lord Brock and his colleagues published at page 598 of the B.M.F. this week sheds light on this question, for it shows that emboli can sometimes be removed months after impaction. Many cardiovascular surgeons have operated on pulmonary and peripheral arterial emboli after impaction and found some: to be irremovable and others loose. More information is. required about the natural history of emboli. Though they undergo lysis spontaneously and rapidly in the dog, ${ }^{13}$ there is ample clinical evidence to prove that this does not always happen in man. The increasing use of pulmonary embolectomy should expand our knowledge of the local lesion in the pulmonary artery.

The present trend is to be bold not only to save life but also to reduce the late morbidity. But this approach needs to be continually reviewed in accordance with the findings at operation and the long-term results.

\section{Doctors' Diseases}

In the evidence which the B.M.A. submitted to the Goodenough Committee it deplored the failure of the medical schools to exclude men and women who, though able to pass examinations, have not the requisite aptitude, character, or staying power for a medical career. The Committee agreed, and recommended ${ }^{1}$ that there should be machinery not only to select students from this standpoint but also to weed out students who prove unsuitable. No one, however, was bold enough to state the criteria of rejection, or, more specifically, to say whether a propensity to some form of psychological illness should be regarded as a sign of unsuitability. Deans of medical schools might have very discrepant views on this matter, and on their ability to look sufficiently into the future of some nervous aspirant aged 18 or 19 to foretell his professional fitness or inadequacy. Nevertheless, the attempt has to be made, for the health and mental stability of doctors are matters of public as well as private concern. It is therefore understandable that the authors ${ }^{2}$ of a recent inquiry should express their surprise that there have been few studies of the amount of psychiatric illness in the medical profession. Their own findings are not particularly encouraging.

A hundred and ninety-two doctors who had been treated at either St. Andrew's Hospital, Northampton, or St. George's Hospital, London, were compared with "control" groups, presumably free from psychiatric illness. There were no differences between the doctors and non-medical patients (matched for age, sex, and social class) in the frequency of most sorts of disorder, except that neurotic depressive reactions and drug addiction were more common in doctors. Psychiatrically disturbed doctors showed a greater tendency than usual to fall by the wayside professionally ; only $70 \%$ were on the Medical Register when followed up in 1964.

The proportions in which various branches of the profession were represented in the sample do not permit any simple conclusion to be drawn. General practitioners made up 53\%, $12 \%$ were psychiatrists, and $11 \%$ were surgeons. A similar investigation $^{3}$ of 93 doctors admitted to the Mayo Clinic for psychiatric treatment between 1956 and 1963 showed that 44 were general practitioners (about the same proportion as in the profession as a whole), 15 were physicians, 17 were surgeons, and 4 were psychiatrists. Evidently no single branch of the profession has a disproportionate pre-eminence in this respect. A third of the doctors had some form of psychotic illness, a fifth were neurotic, and most of the remainder had personality disorders. Treating them was exceptionally difficult because the doctors found it hard to accept the status of a patient and tended to withdraw from treatment too soon.

There are two aspects of psychiatric illness which are painfully prominent in this connexion-suicide and drug addiction. Analysis of the Registrar General's Decennial Supplement earlier in this century ${ }^{4}$ showed that among the occupational groups with the highest suicide rates were doctors and lawyers. It has been conjectured that this was because they "work under some degree of nervous pressure" and witness much misery and suffering. In a recent study ${ }^{5}$ in Oregon the suicide rate for doctors and lawyers was found to be three times as high as in "white-collar workers." Despite the known unreliability of official statistics of suicide, it must be regarded as an occupational disease of medical practice. ${ }^{6}$

The problem of addiction in doctors has also been long recognized. The Rolleston Departmental Committee ${ }^{7}$ that reported in 1926 said that " questions of exceptional difficulty have presented themselves in the cases of doctors who are themselves addicts," and the Brain Committee ${ }^{8}$ echoed this, pointing out that the number of doctors known to be addicts was disproportionately high. There were in Britain in 1960 68 "professional" addicts-doctors, dentists, pharmacists,

\footnotetext{
1 Report of the Inter-departmental Committee on Medical Schools, 1944. H.M.S.O., London. Out of print.

3 A'Brook, M. F., Hailstone, J. D., and McLauchlan, I. E. J., Brit. J. Psychiat., 1967, 113, 1013.

Duffy, J. C., and Liten, E. M., F. Amer. med. Ass., 1964, 189, 989.

Dublin, L. I., and Bunzel, B., To be or not to be-a study of suicide, 1933. New York.

Blachly, P. H., Osterud, H., and Josslin, R., New Engl. F. Med., 1963, 268, 1278.

- Brit. med. f., 1964, 1, 789. Report of the Departmental Committee on Morphine and Heroin
Addiction, 1926. H.M.S.O., London.

- Drug Addiction: Report of, the Interdepartmental Committee, 1961. H.M.S.O., London.

- Ehrhardt, Ḧ., Bull. Narcot., 1959, 11, No. 1, p. 18.

10 Pearson, M. M. and Strecker, E. A., Amer. f. Psychiat., 1960, 116. 915.

11 Putnam, P. L., and Ellinwood, E. H., ibid., 1966, 122, 745.

12 Evans, J. L., ibid., 1966, 122, 159.
} 
and veterinary surgeons-constituting $15 \%$ of the total number of known addicts. According to the report sent to the United Nations from the United Kingdom doctors made up $81 \%$ of all the known "professional addicts," including nurses. As always where drug abuse is concerned, the number of officially known addicts is almost certainly a much lower figure than the real situation would disclose. M. F. A'Brook and his colleagues ${ }^{2}$ had among their 192 patients 30 who were addicted to some drug other than alcohol.

In Germany ${ }^{9}$ there were in 19574,861 addicts, of whom $12 \%$ were doctors. One doctor in 112 was an addict. Reports from the United States deal for the most part with selected populations of doctors - those treated in private ${ }^{10}$ or in the special hospital for addicts at Lexington, Kentucky. ${ }^{11}$ Many psychopathological explanations of the development of addiction in these doctors have emerged from the intensive study they received, but there can be little doubt that the most potent factor in giving them an unhappy pre-eminence among addicts has been the easy access to drugs (though this is not of course the only important factor). It is noteworthy in this connexion that in a study by J. L. Evans ${ }^{12}$ of 50 doctors' wives who received treatment in a private psychiatric hospital between 1960 and 196310 had overuse of drugs as their major presenting symptom, and 12 others had a history of overuse of addictive drugs (apart from alcohol). Fourteen of these 22 women had used morphine or morphine derivatives. Evans concludes that the addiction was related "dynamically and empirically to the profession of the husbands." A number of the women had continued to have ready access to drugs after the addiction was evident.

Can nothing be done to reduce the numbers of doctors' lives wasted by these occupational hazards? Too often, perhaps, colleagues who are aware that all is not well stand aside and refuse to interfere when early action is essential.

\section{Arthritis and Sarcoidosis}

Sarcoidosis is a widespread granulomatous process the signature of which is the sarcoid nodule. This is demonstrable by biopsy and sufficiently characteristic and uniform under the microscope to imply that sarcoidosis has a single cause, but the occurrence of an identical sarcoid reaction to beryllium disease and to some fungal infections proves otherwise. Beryllium disease and fungus infections of this type, however, are rare, and sarcoidosis without exposure to these agents is fairly common, so experts in the disease may be forgiven if they continue to write about sarcoidosis and not about the "sarcoidoses." This apparently academic point is of practical importance in assessment of the prognosis of the condition and its associated manifestations such as arthritis.

A variety of quite different joint conditions have been described as associated with sarcoidosis. The value of studies of this kind is limited if several types of sarcoidosis are lumped together in the reported series. This is particularly so when the Kveim reaction (an artificially induced local sarcoid nodule) is used as proof of the disease. Statistics based on hospital studies are notoriously fallible when it comes to describing apparent association between diseases whose causes are unknown. The "two-disease fallacy" creeps in-the interesting possessor of two diseases is far more likely to be written about than the humdrum patient with only one. Epidemiological studies might be expected to help to clarify the association between arthritis and sarcoidosis, and a valuable survey has been reported by I. Sutherland, D. N.
Mitchell, and P. D'A. Hart, who looked for the development of sarcoidosis in a 14-year prospective follow-up study of 54,239 children and adolescents vaccinated against tuberculosis or observed as unvaccinated controls. They found 52 cases and mentioned that only three of them had joint pains. Nevertheless, workers in hospitals continue to find a high incidence of arthritis in histologically proved sarcoidosis, and in some patients this may be the presenting complaint.

The problem has been looked at both in rheumatism clinics (where the selection factor for arthritis is to be expected, and in specialized sarcoidosis clinics, as in a recent study by J. M. Gumpel and his colleagues. ${ }^{2}$ If nonspecific or unrelated causes of joint symptoms are excluded at least three different presentations of arthritis emerge. The first, wellcharacterized, is an acute arthritis predominantly of the knees and ankles, occurring with or often before erythema nodosum The characteristic patient is in the third or fourth decade and is more often a woman, and the associated clinical features include a painful oedema of the ankles and feet, marked and sometimes incapacitating stiffness of the limbsespecially in the mornings-fever, enlarged hilar lymph nodes, and general malaise. The response of the arthritis to corticosteroids is excellent and complete recovery is the rule, at least in Britain. Anergy to tuberculin and biopsy evidence of sarcoidosis in lymph nodes or other tissues in a small proportion of cases has led to this condition being classified as an arthritis of sarcoidosis, but neither the sarcoidosis nor the arthritis leaves any permanent residue. A positive Kveim test is common and by itself has been accepted as histological proof of sarcoidosis-for example, by Dr. D. G. James and his associates. ${ }^{3}$ Sutherland and his colleagues, however, thought that the Kveim positivity had "some immunological basis not directly related to sarcoidosis." In other words, the presence of a positive Kveim test by itself should not be taken as histological proof of sarcoidosis. Many would feel that it would be preferable to regard this acute, early, and clinically distinct form of arthritis as no more than a part of the "erythema nodosum syndrome" and, as L. H. Truelove $e^{4}$ suggested, " as independent of the underlying cause of the syndrome, whether this be sarcoidosis, tuberculosis, or drug sensitivity."

Two other forms of arthritis associated with sarcoidosis reflect the granulomatous invasion of the para-articular bone or of the synovium. They are much less common, much more likely to become chronic, and they are always associated with clinically apparent granuloma formation in the skin, lung parenchyma, eyes, lymph nodes, or peripheral nerves. Sarcoid dactylitis may give swollen painful fingers, which resemble rheumatoid arthritis superficially, but the radiograph will show the diffuse osteitis in the phalanges-3n appearance which is seen much more frequently than the often quoted punched-out cysts. Synovial lesions ${ }^{\text {s }}$ may take the form of localized plaques of sarcoid-containing tissue, which replace part of the synovium and are associated with a nonspecific reaction elsewhere in the joints. The clinical course of such lesions is variable but usually takes the form of a subacute and recurrent hydrarthrosis. Both the arthritis

\footnotetext{
Sutherland, I., Mitchell, D. N., and Hart, P. D'A., Brit. med. F., 1965

2 Gumpel. J. M., Johns, C. J., and Shulman, L. E., Ann. rheum. Dis. $1967,26,194$

3ames, D. G., Thomson, A. D., and Willcox, A., Lancet, 1956, 2, 218

Truelove, L. H., Ann. rheum 'Dis.. 1960, 19, 174.

- Bianchi, F. A., and Keech, M. K., ibid., 1964, 23, 463.

- Bonnet, W. L., Radiology, 1946, 47, 175.

Kunkel, H. G., Simon, H. J., and Fudenberg, H., Arthr. and Rheum. $1958,1,289$.

- Kaplan, H., and Klatskin, G., Yale Ұ. Biol. Med., 1960, 32, 335.
} 